\title{
TRATO COM O CONTEÚDO ESPORTE NAS AULAS DE EDUCAÇÃO FÍSICA ESCOLAR: DO DISCURSO À PRÁTICA ATUAL
}

Volni Fernando Martins, Universidade Federal de Ouro Preto - UFOP, Ouro Preto, Minas Gerais - Brasil

Jairo Antônio Paixão, Universidade Federal de Ouro Preto - UFOP, Ouro Preto, Minas Gerais - Brasil

\section{RESUMO}

O estudo analisou, de forma crítica, como ocorre, no momento atual, o trato com o conteúdo esporte nas aulas de Educação Física. Considerou-se o trabalho realizado por professores atuantes em escolas da rede pública e particular da cidade de Ouro Preto, MG. Empregou-se a técnica da observação e um questionário, embasado em literatura específica, com questões abertas e fechadas estruturadas a partir da escala Likert de três pontos. Os resultados obtidos expressam que, mesmo após duas décadas de movimentos e discussões que criticam a forma como o esporte se insere na escola, mantém-se um quadro em que o esporte detém a hegemonia dentre os demais conteúdos assumindo função legitimadora não só do professor, mas da própria Educação Física como componente curricular.

Palavras-Chave: Educação física; Esporte; Escola.

\section{EL TRATAMIENTO DEL DEPORTE EN CLASES DE EDUCACIÓN FÍSICA: EL DISCURSO A LA PRÁCTICA ACTUAL}

\section{RESUMEN}

Este estudio, analizó, críticamente, como ocurre en el momento presente, el tracto con contenido deportivo en las clases de educación física. La investigación tomó en cuenta el trabajo realizado por los profesores que trabajan en las escuelas públicas y escuelas privadas de la ciudad de Ouro Preto, MG. Se aplicó la técnica de observación y un cuestionario, basado en la literatura, con preguntas abiertas y cerradas estructurados a partir de los tres puntos de las preguntas de escala Likert. Los resultados expresan que aún después de dos décadas de discusiones y movimientos que critican la forma en que el deporte se inserta en la escuela, un marco que sostiene la hegemonía deporte entre los otros contenidos que asumen la función de legitimar no sólo del maestro sigue siendo, pero la educación muy físico como un componente curricular.

Palabras-Clave: Educación física; Deporte; Escuela. 


\title{
THE TREATMENT OF SPORTS IN PHYSICAL EDUCATION CLASSES BASED ON THE TEACHER'S SPEECH
}

\begin{abstract}
This study analyzed how the treatment of sports subject occurs, in present moment, in physical education classes. The work was held by teachers in both private and public schools in Ouro Preto, MG. Observation technique and a questionnaire was applied, supporting a specific literature and with open and close-ended questions using the threelevel Likert scale. An establishment is kept which the sport holds an hegemony around others subjects, taking a legitimizing role, not only in the teaching, but also in the school Physical Education.
\end{abstract}

Key-Words: Physical Education; Sport; School. 


\section{INTRODUÇÃO}

O esporte configura-se como um dos mais importantes fenômenos sociais ocorridos nos últimos tempos. Nas palavras de Tubino, ${ }^{1}$ fatores como o aumento considerável do número de praticantes, bem como o surgimento ininterrupto de novas modalidades esportivas, sob diferentes perspectivas, reforçam a relevância do esporte como um dos fenômenos mais expressivos ao longo dos tempos. Essa notoriedade do esporte configura-se de forma semelhante na escola, mais precisamente, como conteúdo das aulas de Educação Física. ${ }^{2}$

Dentre os temas sugeridos pela Cultura Corporal de Movimento como a dança, a ginástica, os jogos e as lutas, ${ }^{3}$ percebe-se a soberania do esporte que mantém, ao longo dos tempos, uma inabalável hegemonia se comparado com os demais conteúdos selecionados pelos professores para serem trabalhados nas aulas.

Tem-se a partir da segunda metade da década de 1980, embasados pelas pedagogias críticas da Educação Física, um significativo desenvolvimento da produção acadêmica que tem como objeto a Educação Física na Educação Básica. Sem a pretensão de esgotar a produção na área, merecem destaque aquelas empreendidas por autores como Soares et al., ${ }^{3}$ Kunz, ${ }^{4}$ Vago, ${ }^{5}$ dentre outros que preconizaram uma discussão que perdura nos dias atuais sobre a relação que a Educação Física escolar estabelece, ou deveria estabelecer, com o esporte de rendimento. Foram levantadas discussões célebres como, por exemplo, o sentido do esporte da escola e o esporte na escola enquanto um alerta aos professores sobre a necessidade de uma transformação didática pedagógica do esporte. ${ }^{4}$

As críticas, envolvendo o trato do esporte no âmbito escolar e seu sentido polissêmico na formação do indivíduo na década de 1990, reverberam ainda no contexto acadêmico atual e se constituem como referências para entender a relação que se estabelece entre Educação Física escolar e esporte. ${ }^{6}$

A partir de constatações empíricas como aquelas presentes na literatura especifica atual, ${ }^{7-8}$ percebe-se que o esporte como conteúdo nas aulas de Educação Física ainda parece não ter se definido na forma como é entendido e trabalhado pelos professores Conexões: revista da Faculdade de Educação Física da UNICAMP, Campinas, v. 12, n. 3, p. 18-33, jul./set. 2014. 
dessa área do saber. Tal situação leva a pensar que, ainda hoje, os professores de Educação Física parecem estar sob a influência da concepção esportivista, com seus códigos e valores relacionados ao rendimento, restringindo os conteúdos das aulas aos esportes, nomeadamente, às modalidades mais tradicionais como futsal, vôlei, handebol e basquete. ${ }^{9}$ Situação essa denominada por Paes ${ }^{10}$ como prática repetitiva de gestos técnicos em diferentes níveis de ensino, haja vista que, na maioria das vezes, o mesmo conteúdo se repete desprovido de qualquer tipo de adequação para os diferentes segmentos que compõem a Educação Básica.

A realidade mostra que, no âmbito da educação formal, as mudanças na forma como se vincula o conteúdo esporte nas aulas de Educação Física são complexas. Há uma série de elementos que dificultam as mudanças como, por exemplo, as finalidades com que se deu a inserção da Educação Física como componente curricular na escola, o imaginário popular e o status de fenômeno social atribuído ao esporte no Brasil e no mundo, bem como a sua utilização como elemento alienante das grandes massas populares pela classe dominante. $^{2}$

De tempos em tempos, tem-se acompanhado o lançamento de uma série de programas e projetos por parte do governo nos quais a tônica volta-se para o binômio esporte/escola. Em se tratando de uma fase que antecede os megaeventos no Brasil, essas propostas tem-se se intensificado. Nessa perspectiva, subvertendo a lógica da formação escolar, em sua maioria, trata-se de iniciativas que chegam envoltas por belos, antigos e vazios discursos ufanistas que almejam, sobretudo, revelar atletas em potencial na escola. Haja vista que essas iniciativas surgem de forma fragmentada, sem pretensão de continuidade e sem levar em consideração os diferentes contextos em que se encontram as escolas nas regiões brasileiras. Um exemplo recente e que tem causado certa polêmica no meio acadêmico é o plano Brasil Medalhas 2016, que foi lançado pela presidenta Dilma Rousseff e pelo Ministro do Esporte, Aldo Rebelo, tem como objetivo colocar o Brasil entre os dez primeiros países nos Jogos Olímpicos e entre os cinco primeiros nos Jogos Paraolímpicos do Rio de Janeiro, em 2016. Em síntese, trata-se da promoção de provas de salto em distância e corridas de velocidade nas aulas de Educação Física em busca de talentos que faltam ao esporte olímpico brasileiro. Dentre as críticas que se tem acompanhado sobre esse plano, em específico, destacam-se aqui as palavras de João Conexões: revista da Faculdade de Educação Física da UNICAMP, Campinas, v. 12, n. 3, p. 18-33, jul./set. 2014. 
Batista Freire $^{11}$ ao afirmar que quando um aluno recebe uma aula de matemática, supõese que o professor não vê nele um futuro matemático, mas um futuro cidadão, que até pode vir a ser um matemático. Na disciplina química, também o que está em jogo é a formação do cidadão; supõe-se que aprendendo química sua chance de viver eticamente aumenta. Na mesma direção, nas aulas de Educação Física escolar, o bom professor não concebe o seu aluno como um atleta, mas um cidadão, que deve ser respeitado em seus direitos de aprender e poder escolher maneiras de conduzir bem sua vida individual e social. ${ }^{11}$ Outro exemplo dessas iniciativas é o Programa de Formação Esportiva Escolar, mais conhecido como Atleta na Escola que, subsidiado pelo Ministério da Educação, volta-se às escolas públicas e privadas de Educação Básica.

Ainda que de forma parcial, o quadro apresentado fornece elementos para se pensar Educação Física na escola e a relação que se estabelece com o conteúdo esporte.

Nessa perspectiva, o presente estudo buscou analisar, como os professores trabalham o conteúdo esporte nas aulas de Educação Física no ensino fundamental II ( $6^{\circ}$ ao $9^{\circ}$ ano) e ensino médio ( $1^{\circ}$ ao $3^{\circ}$ ano) em escolas das redes pública estadual e particular da cidade de Ouro Preto, MG.

\section{O ESPORTE E O DISCURSO DA LEGITIMIDADE E AUTONOMIA DA EDUCAÇÃO FÍSICA NA ESCOLA}

Indubitavelmente, o esporte detém o status de expressão hegemônica da cultura de movimento na sociedade atual. De forma semelhante, o é no contexto escolar. Diferentes razões, como afirma Bracht, ${ }^{12}$ vêm ao longo dos tempos, contribuindo para que o esporte se configure como conteúdo dominante na escola, como, por exemplo, o entendimento pelo sistema esportivo da escola como "base" para o seu desenvolvimento, sua vinculação com a saúde, sustentado pelo binômio esporte-saúde.

A atribuição de termos como fenômeno e instituição social pelos estudiosos, quando se referem ao esporte, apenas confirma a abrangência dessa prática corporal na sociedade aos longos dos tempos. Trata-se do esporte que se assenta sobre os códigos do rendimento, da competição e, sobretudo, do espetáculo nos moldes de produção de uma sociedade capitalista. No âmbito da escola, mais precisamente nas aulas de Educação 
Física, o esporte trabalhado reproduz os mesmos códigos vigentes na sociedade em um dado momento histórico.

A partir da década de 1980, embasados pelos pressupostos da sociologia crítica do esporte e teorias críticas da educação e Educação Física ${ }^{2-4}$ iniciaram-se, de forma contundente, pela comunidade acadêmica debates e críticas sobre o esporte de rendimento na escola, tendo como pano de fundo as finalidades e objetivos da Educação Física escolar, a busca por sua legitimidade, bem como a dimensão educativa e/ou formação do aluno por meio da referida prática pedagógica e seus conteúdos presentes na instituição escolar. ${ }^{12}$

Neste cenário, evidencia-se um paradoxo no qual o trato do esporte, nos moldes de rendimento na escola pela Educação Física (esporte na escola), representaria uma forma de legitimar seu papel enquanto componente curricular. Por outro lado, o esporte, desprovido de transformação didático-pedagógica, visando sua adequação enquanto tema da Cultura Corporal de Movimento (esporte da escola), representaria a expressão máxima de não autonomia enquanto prática de intervenção pedagógica. ${ }^{12}$

$\mathrm{Na}$ proposta de $\mathrm{Kunz}^{4}$ sobre a necessidade de transformação didático pedagógica do esporte no âmbito escolar, tem-se esse conteúdo desenvolvido de forma a transcender o reducionismo da prática pela prática numa perspectiva inclusiva. Nessa perspectiva, ao longo do processo ensino aprendizagem, o professor oportunizaria ao aluno ter condições de não somente praticar o esporte, mas também, percebê-lo como fenômeno histórico-cultural construído pelo homem, passível de modificações e atualizações para situar-se numa dada sociedade, num dado momento. Ainda nesse contexto, as aulas de Educação Física escolar deveriam se configurar como espaços nos quais os alunos sejam capazes de refletir sobre as diferentes representações do esporte no meio social como, por exemplo, o esporte e a influência midiática, sua mercantilização e esportivização, promoção de saúde e a potencialização do consumo de produtos pelo e para o esporte. No entanto, o ideal esportivo, que se desenvolveu notavelmente no Brasil nos anos de 1960 e 1970, continua forte e ainda é o principal elemento legitimador da Educação Física escolar. ${ }^{8}$ 


\section{METODOLOGIA}

A fim de analisar aspectos ligados ao trato do conteúdo esporte por professores de Educação Física na escola foi realizada uma pesquisa de natureza descritiva. ${ }^{13-14}$ Os participantes deste estudo constituem uma amostra de 13 professores, sendo 04 do gênero masculino e 09 do gênero feminino com uma média de idade 35,4 e desvio padrão $\pm 8,9$, atuantes em escolas da rede pública e particular da cidade de Ouro Preto, MG. Vale ressaltar que esses sujeitos se formaram na última década e encontravam atuando nos anos finais do Ensino Fundamental ( $6^{\circ}$ ao $9^{\circ}$ ano) e Ensino Médio.

Para a coleta dos dados, foram utilizados como instrumentos observação ${ }^{15}$ e um questionário semiestruturado. A observação consiste no registro sistemático, válido e confiável de comportamento ou conduta manifesta. ${ }^{15}$ Dentre os passos adotados na construção do sistema de observação, segundo os mesmos autores, buscou-se inicialmente definir com precisão o universo de aspectos e condutas a serem observadas no cotidiano dos professores no decorrer das aulas, como, por exemplo, os conteúdos trabalhados, forma de abordagem desses conteúdos, bem como a participação e aceitabilidade por parte dos alunos e outros eventos que pudessem ocorrer ao longo do período de observação; daí extraiu-se uma amostra representativa desses aspectos e condutas observadas definindo-se as unidades de observação a serem consideradas no presente estudo, estabelecendo a partir desse ponto as categorias e subcategorias da observação realizada. O questionário foi estruturado com questões abertas e fechadas, sendo que as questões fechadas foram estruturadas a partir da escala Likert de três pontos, ${ }^{16}$ que permitia aos entrevistados apresentar três níveis de concordância para um item, variando do número 1 para o principal motivo, 2 para o segundo motivo e 3 para o terceiro principal motivo em ordem de importância. Ao final de cada questão, havia espaço destinado a oferecer ao entrevistado a oportunidade de emitir resposta diferente, caso não se identificasse com as alternativas apresentadas. O referido instrumento de coleta de dados continha 12 questões dispostas a partir de três categorias que buscavam levantar as seguintes informações: caracterização dos sujeitos da pesquisa; aspectos relacionados à seleção de conteúdo pelo professor e ainda, motivos, tipo de abordagem e percepção das finalidades de se trabalhar o esporte nas aulas de Educação Física. Ao longo do período em que se deu a coleta de dados (junho a setembro de 2012), foram 
observadas 10 aulas de Educação Física por turma, sendo uma do $6^{\circ}, 7^{\circ}, 8^{\circ}$ e $9^{\circ}$ ano do ensino fundamental II e ainda uma turma do $1^{\circ}$ e $2^{\circ}$ ano do ensino médio.

Na elaboração das Figuras 2, 3 e 4, foi considerado apenas o nível de concordância de número 1 que se referia ao principal motivo nos itens das questões apresentadas aos entrevistados.

$\mathrm{Na}$ análise dos dados coletados a partir das questões abertas do questionário, foi empregada a técnica de análise de conteúdo, proposta por Bardin. ${ }^{17}$ Desta forma, inicialmente foi analisado o conteúdo contido nas respostas dos participantes, para então se estabelecer uma identificação de categorias sistemáticas e suas respectivas correlações num momento posterior. Na organização e análise dos dados coletados, foi utilizado o programa N-Vivo 9, versão em português.

Vale ressaltar que, antes da aplicação dos questionários, foi explicado aos participantes o objetivo do estudo e que eles tinham liberdade para participar ou não da pesquisa. Assim, todos eles assinaram um Termo de Consentimento Livre e Esclarecido.

No decorrer do processo de condução da presente pesquisa, foram respeitadas as diretrizes regulamentadas pela Resolução $n^{\circ} 466 / 12$ da CONEP, sendo o projeto aprovado pelo Comitê de Ética em Pesquisa com seres humanos com o registro de número 0783/2012.

\section{RESULTADOS}

Ao analisar os conteúdos trabalhados pelos professores nas aulas de Educação Física, como apresenta a Figura 1, percebe-se a ênfase dada ao conteúdo esporte, que surge como a primeira opção de conteúdo pelos professores no planejamento letivo. Na sequência, os conteúdos jogos, dança e brincadeiras surgem numa frequência significativamente inferior àquela referente ao conteúdo esporte. 


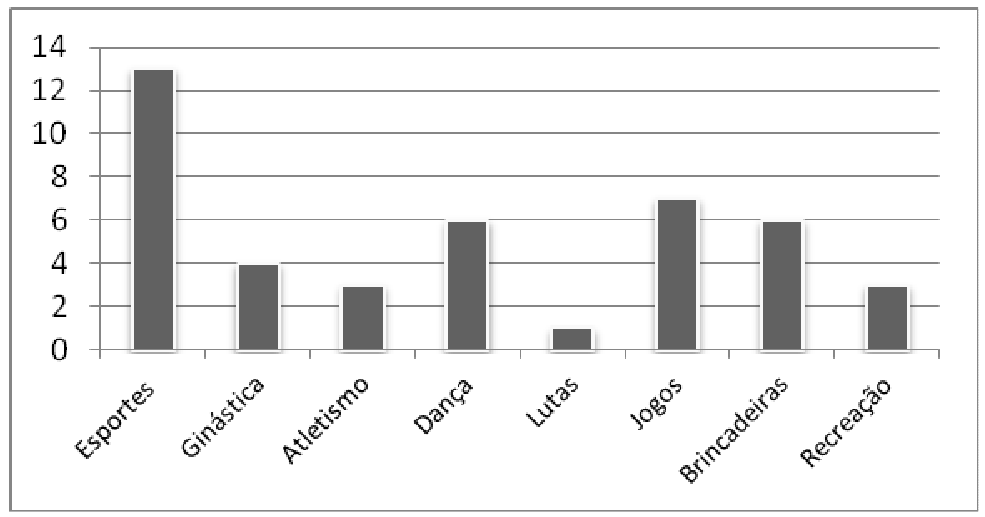

Figura 1: Conteúdos trabalhados pelos professores nas aulas de Educação Física.

Dentre os principais motivos que contribuem para que o esporte seja o conteúdo privilegiado nas aulas de Educação Física, destacam-se variáveis como 'Por ser um fenômeno sociocultural brasileiro' 61\%, seguido por 'É interessante para a maioria dos alunos' com 23\% e com $8 \%$ as opções 'Conteúdo comum à vivência dos alunos' e 'Por melhor contribuir na formação dos alunos' $8 \%$.

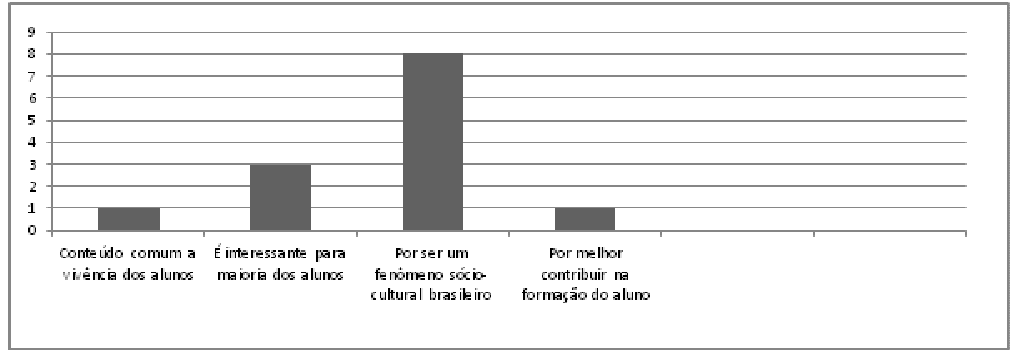

Figura 2: Principais motivos de se trabalhar o esporte nas aulas de Educação Física.

$\mathrm{Na}$ definição de objetivos que buscam atingir ao se trabalhar o conteúdo esporte nas aulas é possível observar nos resultados apresentados na Figura 3 que, dentre os professores entrevistados, 30,8\% buscam desenvolver a criticidade dos alunos, $23 \%$ a formação dos valores morais e comportamentais. A aquisição e manutenção da saúde e condicionamento, visando à prática de exercícios físicos, aparecem numa frequência de 23\%. Já os objetivos que se relacionam a preparar os alunos para a prática de atividades recreativas se apresentam em um total de 15,6\%. Quanto aos objetivos com vistas ao desenvolvimento motor dos alunos, tem-se um percentual de 7,6\% dos professores que trabalham o referido conteúdo em suas aulas. 


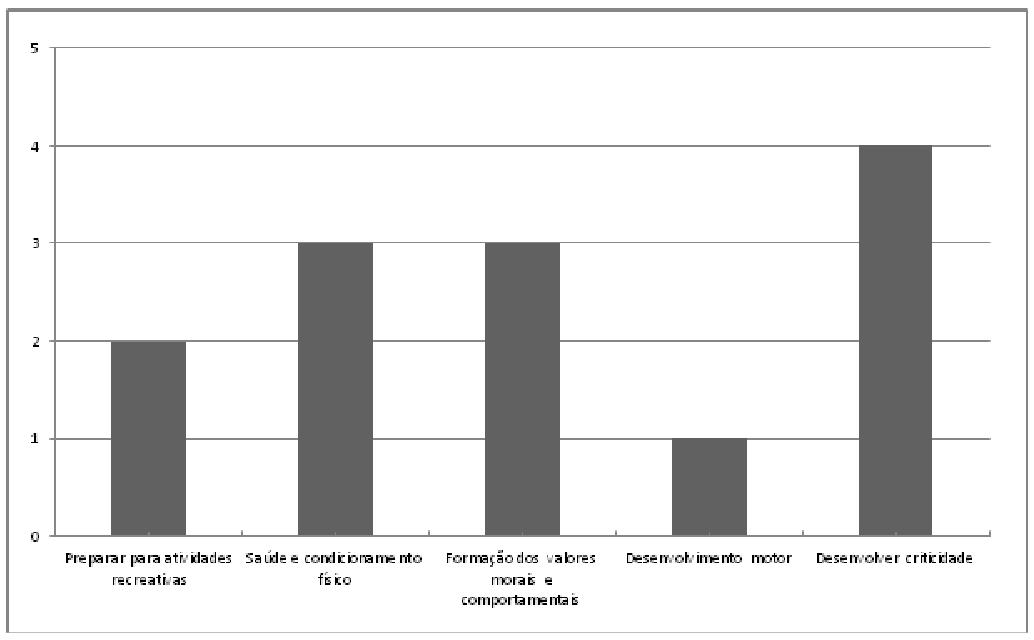

Figura 3: Objetivos buscados com o trabalho de esporte nas aulas.

Quanto à percepção dos professores sobre o esporte enquanto conteúdo nas aulas de Educação Física, os resultados apresentados na Figura 4 mostram o esporte como o conteúdo de maior aceitação pelos alunos $(38,5 \%)$ e importante elemento que contribui para legitimar a Educação Física perante a comunidade escolar $(38,5 \%)$. Nota-se a equanimidade e prevalência entre essas duas variáveis quando relacionada a uma terceira que o considera como o principal conteúdo das aulas de Educação Física escolar $(23 \%)$.

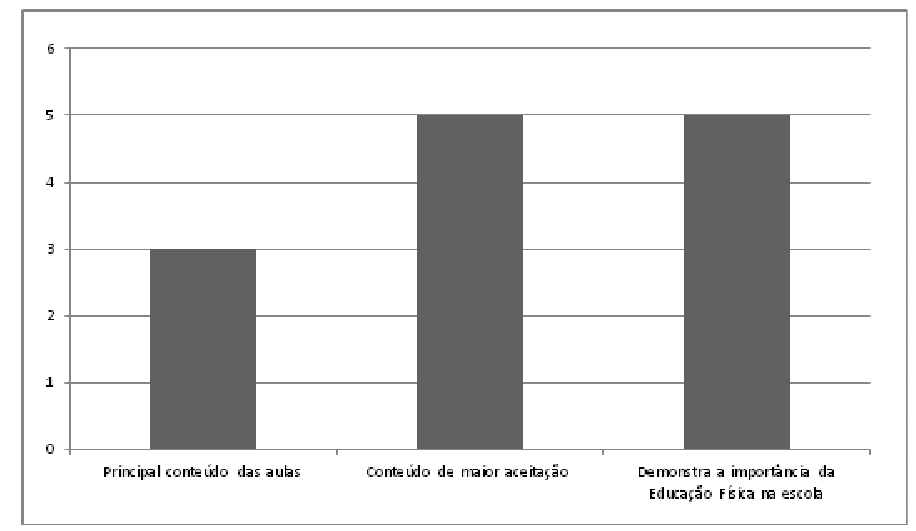

Figura 4: Percepção do conteúdo esporte nas aulas de Educação Física pelos professores.

\section{DISCUSSÃO}

A análise realizada sobre a Educação Física escolar, tendo como eixo norteador o trato do esporte pelos professores, corrobora uma situação destituída de qualquer resquício de ineditismo no âmbito das pesquisas que se voltam para esse campo de intervenção e que vem sendo produzido ao longo das últimas décadas (FIGURA 1). Tem-se o conteúdo 
esporte que se mantém, confortavelmente, alicerçado sob uma hegemonia já anunciada, denunciada e criticada por um volume considerável de estudos iniciados nos anos de $1980 .^{2-6,12,18}$

Ao se considerar a Educação Física como componente escolar e suas finalidades para/na formação do aluno, tem-se como característica fundante dos estudos que analisam o esporte como conteúdo das aulas de Educação Física, a problemática, o esporte trabalhado no interior das escolas que, em sua maioria, são regidos por códigos que o estruturam sob a égide do rendimento, da espetacularização e do mercantilismo e, que, por sua vez, é amplamente difundido pelos meios de comunicação de massa no meio social. $^{2,19}$

Os principais motivos de se trabalhar o conteúdo esporte nas aulas (FIGURA 2), apontados pelos professores, coadunam com os pressupostos teóricos apresentados pelas abordagens críticas, mencionadas ao longo desse texto, que toma os conteúdos e a forma de abordá-los como elementos históricos e culturais produzidos pelo homem, ao longo dos tempos. Desta análise destacam-se motivos como o fato de o mesmo deter o status de fenômeno sociocultural brasileiro e, consequentemente, o interesse que desperta nos alunos. Somado a isso, tem-se dentre os objetivos almejados com o trabalho do esporte em suas aulas, o desenvolvimento da criticidade, formação de valores que surgem como os objetivos principais e na sequência, numa menor frequência, aqueles aspectos que se relacionam ao desenvolvimento motor, condicionamento e práticas físicas (FIGURA 3).

No entanto, em um segundo plano, subvertendo essa lógica, as observações realizadas nas aulas revelam um enorme abismo entre o discurso e a prática desses profissionais. Ratifica-se aqui aquele ditado que expressa que 'na prática a teoria é outra'. Por meio das observações nas diferentes escolas contempladas por esse estudo, ao se considerar o trato com o conteúdo esporte, foi evidenciada uma realidade da qual foi possível estabelecer duas situações: o esporte trabalhado numa perspectiva meramente tecnicista e/ou o esporte praticado pelos alunos, no decorrer das aulas, desprovido da intervenção do professor no que se refere à condução do processo ensino-aprendizagem, o que o remete a uma prática recreacionista, ${ }^{4}$ ou em outras palavras, o habitual 'rola-bola'. 
Ainda que a análise da(s) abordagem(s) adotadas em aulas pelos professores não tenha se constituído o eixo norteador do presente estudo, e que o quadro apresentado não seja dos mais otimistas e indicativos de mudanças, foi possível apreender, entre os professores que fizeram parte desse estudo, indícios nas respostas dos professores que revelavam a preocupação com questões de gênero e no oferecimento aos alunos de uma formação crítica no âmbito da Educação Física (FIGURA 3). No entanto, a adoção de uma abordagem crítica de ensino por esses profissionais não se mostrou materializar em suas aulas. Uma problemática que certamente demanda mais pesquisas na área. Pois, a presença das abordagens críticas de ensino nas matrizes curriculares dos cursos de licenciatura em Educação Física, em disciplinas como Metodologia do Ensino, Didática da Educação Física, Prática de Ensino e outras não tem sido capaz de transformar/alterar a prática do professor nas aulas de Educação Física. Isso, somado ao fato de que o movimento renovador se firmou nos primeiros anos da década de 1990 e que, os professores que fizeram parte desse estudo se formaram nas últimas décadas, denota um quadro ao mesmo tempo curioso e preocupante em termos de intervenção profissional. Ainda que de forma empírica, a realidade proporciona elementos para se refletir acerca do problema. Uma intervenção pedagógica estruturada por meio de planejamento que se efetiva ancorada por pressupostos de uma abordagem crítica ou acrítica de ensino, certamente, demanda uma dedicação prévia que muitos professores de Educação Física parecem ter aversão.

Foi ressaltado nesse texto, com base nos dados apresentados na FIGURA 2, que dentre os motivos em se trabalhar com o esporte nas aulas, destaca-se o fato de esse conteúdo ser considerado um fenômeno sociocultural no Brasil pelos professores. Pois bem, nessa esteira de discussão, tem-se que levar em consideração que do ponto de vista sociocultural parece persistir um entendimento equivocado de Educação Física e esporte como mesmo significado. Trata-se de uma situação que se percebe no imaginário infantil. Geralmente, os alunos, nos primeiros anos da Educação Básica chegam à escola com essa concepção. E com um agravante: Educação Física e esporte se mesclam numa vertente eminentemente prática. Um exemplo pode ser percebido quando o professor busca considerar no trato com um conteúdo, para além da dimensão procedimental, a dimensão conceitual e a atitudinal. Ainda que as referidas dimensões do conteúdo encontram-se imbricadas e podem ocorrer de maneira simultânea durante um momento 
da instrução, ${ }^{18}$ é comum se ouvir por entre os alunos questionamentos do tipo 'quando a aula vai começar?', 'solta a bola professor!'... O problema é que essa visão equivocada do significado de Educação Física e de esporte parece permanecer e, com as devidas exceções, nem mesmo, os anos em que o acadêmico permanece no curso de licenciatura em Educação Física parecem contribuir muito para descontruir o conceito.

Dentre os temas tratados pela Educação Física na escola, o conteúdo esporte apresentase não somente o principal como também o mais aceito pelos alunos (Figura 4). Nesse campo favorável, o esporte é percebido pelos professores como o conteúdo que enaltece a importância de sua área de intervenção junto aos alunos e a comunidade escolar. Esse entendimento sobre o esporte ultrapassa os muros escolares e se encontra presente em discursos, políticas públicas e ações que fomentam o esporte e sua interface no âmbito da escola. Tem-se, como exemplo, já mencionado nesse texto, a iniciativa do Ministério do Esporte denominada Brasil Medalhas 2016. Ao se considerar o contexto histórico, percebeu-se que desde a sua implantação no currículo, em 1882 com o parecer de Rui Barbosa, a Educação Física assumiu características das instituições onde era ministrada, como as influências médica, militar e esportiva. ${ }^{20}$ Nesse sentido, inciativas como o Brasil Medalhas 2016, o Atleta na Escola e outras pela forma como é concebida pelos Ministérios do Esporte e o da Educação remete à década de 1970 em que a escola foi comparada como um celeiro de atletas em potencial, um espaço para descobrir talentos esportivos.

No âmbito do conteúdo esporte, ao se investigar as modalidades esportivas mais trabalhadas nas aulas, o futsal, o vôlei, o handebol e o basquete aparecerem como as mais frequentes, com destaque para as duas primeiras. Esse fato leva a se pensar na ausência de inovação nas aulas e, por sua vez, a manutenção de modalidades esportivas que se encontram em evidência na mídia brasileira.

\section{CONCLUSÃO}

Diante das constatações obtidas nesta investigação e considerando as suas limitações metodológicas, é possível afirmar que a análise realizada a partir do trato do esporte pelos professores nas aulas de Educação Física evidenciou no discurso dos entrevistados 
a influência de pressupostos críticos para o trabalho não só do esporte como dos demais conteúdos da Educação Física na escola. O que não ficou claro é a dimensão em que esses pressupostos se efetivam nas aulas e, por conseguinte, na formação dos alunos, haja vista que no discurso dos professores, o trato com o conteúdo esporte nas aulas possibilita a formação crítica do aluno. No entanto, a prática desses mesmos professores reproduz os códigos e valores comuns ao modelo esportivo vinculado pela mídia na contemporaneidade.

O esporte é um elemento de grande expressividade no campo da Educação Física escolar. Contudo, o que o configura como um potencial conteúdo educativo não está centrado no espetáculo, no rendimento ou na sua popularidade, mas no trato pedagógico que qualquer conteúdo deve estar atribuído para fins educativos dentro do ambiente escolar, sendo este desenvolvido de forma a oportunizar experiências a maior gama de alunos possível e acompanhado de trato reflexivo e formativo para ser realmente formador de cidadãos.

Promover discussões e debates no âmbito de formação inicial, bem como no ambiente da escola, onde se efetivam as práticas de intervenção do professor de Educação Física é um esforço que merece ser concretizado. Desta forma, sugerem-se novas investigações sobre o tema, incluindo análise aprofundada de planejamento, seleção de conteúdo, bem como aspectos relacionados às abordagens pedagógicas para o ensino dos conteúdos da Educação Física.

\section{REFERÊNCIAS}

${ }^{1}$ TUBINO, M. J. G. Dimensões sociais do esporte. 2. ed. São Paulo: Cortez, 2001.

${ }^{2}$ BRACHT, V. Sociologia critica do esporte: uma introdução. Ujuí: Ed. da Unijuí, 2011.

${ }^{3}$ SOARES, C. L. et al. Metodologia do ensino de educação física. São Paulo: Cortez, 1992.

${ }^{4}$ KUNZ, E. Transformação didático pedagógica do esporte. 6. ed. Ujuí: Ed. da Unijuí, 2000.

Conexões: revista da Faculdade de Educação Física da UNICAMP, Campinas, v. 12, n. 3, p. 18-33, jul./set. 2014 
${ }^{5}$ VAGO, T. M. O "esporte na escola" e o "esporte da escola": da negação radical para uma relação de tensão permanente. Movimento, Porto Alegre, v. 3, n. 5, 1996.

${ }^{6}$ MELLO, A. S. et al. Educação física e esporte: reflexões e ações contemporâneas. Movimento, Porto Alegre, v. 17, n. 2, p. 175-193, abr./jun. 2011.

${ }^{7}$ ALMEIDA, A. B.; TUCHER, G.; ROCHA, C. A. Q. Percepção discente sobre a educação física escolar e motivos que levam à sua prática. Revista Mackenzie de Educação Física e Esporte, São Paulo, v. 10, n. 2, p. 109-116, 2011.

${ }^{8}$ Millen NETO, A. R. FERREIRA, A. C.; SOARES, A. J. G. Políticas de esporte escolar e a construção social do currículo de Educação Física. Motriz, Rio Claro, v.17 n. 3, p.416-423, jul./set. 2011.

${ }^{9}$ ROSADO, L. F. R.; DARIDO, S. C. A sistematização dos conteúdos da educação física na escola: a perspectiva dos professores experientes. Motriz, Rio Claro, v.11, n. 3, p. 167-178, 2005. Disponível em:

<http://www.periodicos.rc.biblioteca.unesp.br/index.php/motriz/issue/view/19>. Acesso em: 22 ago. 2012.

${ }^{10}$ PAES, R. R. A Pedagogia do esporte e os jogos coletivos. In: DE ROSE JUNIOR, D. (Org.). Esporte e atividade física na infância e na adolescência: uma abordagem multidisciplinar. Porto Alegre: Artmed, 2002. p. 89-98.

${ }^{11}$ FREIRE, J. B. Não somos caçadores de talentos. Centro esportivo virtual: blog do João Freire. Disponível em: <http://blog.cev.org.br/joaofreire/>. Acesso em: 23 set. 2012.

${ }^{12}$ BRACHT, V. Esporte na escola e esporte de rendimento. Movimento, Porto Alegre, ano 6, n. 12, 2000.

${ }^{13}$ RICHARDSON, R. J. Pesquisa social: métodos e técnicas. 3. ed. São Paulo: Atlas, 1999.

Conexões: revista da Faculdade de Educação Física da UNICAMP, Campinas, v. 12, n. 3, p. 18-33, jul./set. 2014. 
${ }^{14}$ THOMAS, J. R.; NELSON, J. K. Métodos de pesquisa em atividade física. 6. ed. Porto Alegre: Artmed, 2012.

${ }^{15}$ SAMPIERI, R. H.; COLLADO, C. F.; LUCIO, M. D. P. B. Metodologia de pesquisa. 5. ed. Porto Alegre: Artmed, 2013.

${ }^{16}$ LIKERT, R. A Technique for the measurement of attitudes. Archives of Psychology, New York, v. 22, n. 140, p. 1-55, 1932.

${ }^{17}$ BARDIN, L. Análise de conteúdo. 4. ed. Lisboa: Edições 70, 2006.

${ }^{18}$ DARIDO, S. C.; RANGEL, I. A. C. Educação física na escola: implicações para a prática pedagógica. Rio de Janeiro: Guanabara Koogan, 2005.

${ }^{19}$ PRONI, M.; LUCENA, R. Esporte: história e sociedade. Campinas: Autores Associados, 2002.

${ }^{20}$ SOARES, C. Educação física: raízes europeias e Brasil. 4. ed. Campinas: Autores Associados, 2007.

Recebido em: 19 maio 2014 Aceito em: 29 set. 2014 Contato: jaitopaixao@yahoo.com.br 